\title{
Relationship between infarct transmurality and regional myocardial function at different levels of the left ventricle in patients with first-time ST-elevation myocardial infarction Pavel Hala, Anders Thorstensen, Asbjørn Støylen and Brage H Amundsen*
}

Address: NTNU, Trondheim, Norway

* Corresponding author

from 13th Annual SCMR Scientific Sessions

Phoenix, AZ, USA. 21-24 January 2010

Published: 21 January 2010

Journal of Cardiovascular Magnetic Resonance 20 I0, I2(SuppI I):PI55 doi:I0.I I86/I532-429X-I2-SI-PI55

This abstract is available from: http://jcmr-online.com/content/I2/SI/PI55

(c) 2010 Hala et al; licensee BioMed Central Ltd.

\section{Introduction}

The relationship between regional myocardial function and the transmural extent of infarction (TEI) is complex, and there is considerable overlap in wall thickening measurements between normal and infarcted segments. Some of this overlap is caused by tethering from neighbor segments, but could possibly also be caused by errors in wall thickening measurements due to: 1)through-plane motion in basal segments, and 2)oblique orientation of the image plane relative to the left ventricular (LV) wall in apical segments.

\section{Purpose}

To study the relationship between regional functional measurements and the TEI at the basal, mid-ventricular and apical levels of the LV.

\section{Methods}

Fifty-eight patients (44 male, age 58(8) yrs) underwent MRI 32(12) days after a first time STEMI involving the LAD (42\%), CX (22\%) and RCA (36\%). Wall thickness and -thickening were quantified by cine short-axis ssfpimages at $1-\mathrm{cm}$ intervals throughout the LV. TEI was measured using a phase-sensitive inversion recovery sequence in the same slices as the functional imaging, $10 \mathrm{~min}$ after a bolus of $0.15 \mathrm{mmol} / \mathrm{kg}$ gadodiamid. Infarcted myocardium was quantified using a cut-off of 2 SD relative to remote myocardium. All analyses were performed in the Segment software, using the 16 segment AHA model of the LV.

\section{Results}

Infarcted myocardium was found in 387 of 928 segments, and in these segments the average TEI was 27\% (number of segments in different categories: $0 \%: 541 ; 1-25 \%: 223$; 26-50\%:90; 51-75\%:47; 76-100\%:27). For all 928 segments, TEI agreed moderately with absolute and fractional wall thickening $(r=0.53$ and $r=0.51$, respectively, both $\mathrm{p}<0.001)$. There was no significant correlation between TEI and end-diastolic wall thickness. These relationships were similar for basal, midventricular and apical segments (Figure 1).

\section{Conclusion}

During the subacute phase after a first-time STEMI, the relationship between segmental infarct transmurality and segmental wall thickening is moderately strong, and not different at the basal, midventricular and apical levels of the LV. End-diastolic wall thickness cannot be used to predict infarct transmurality during this phase. 

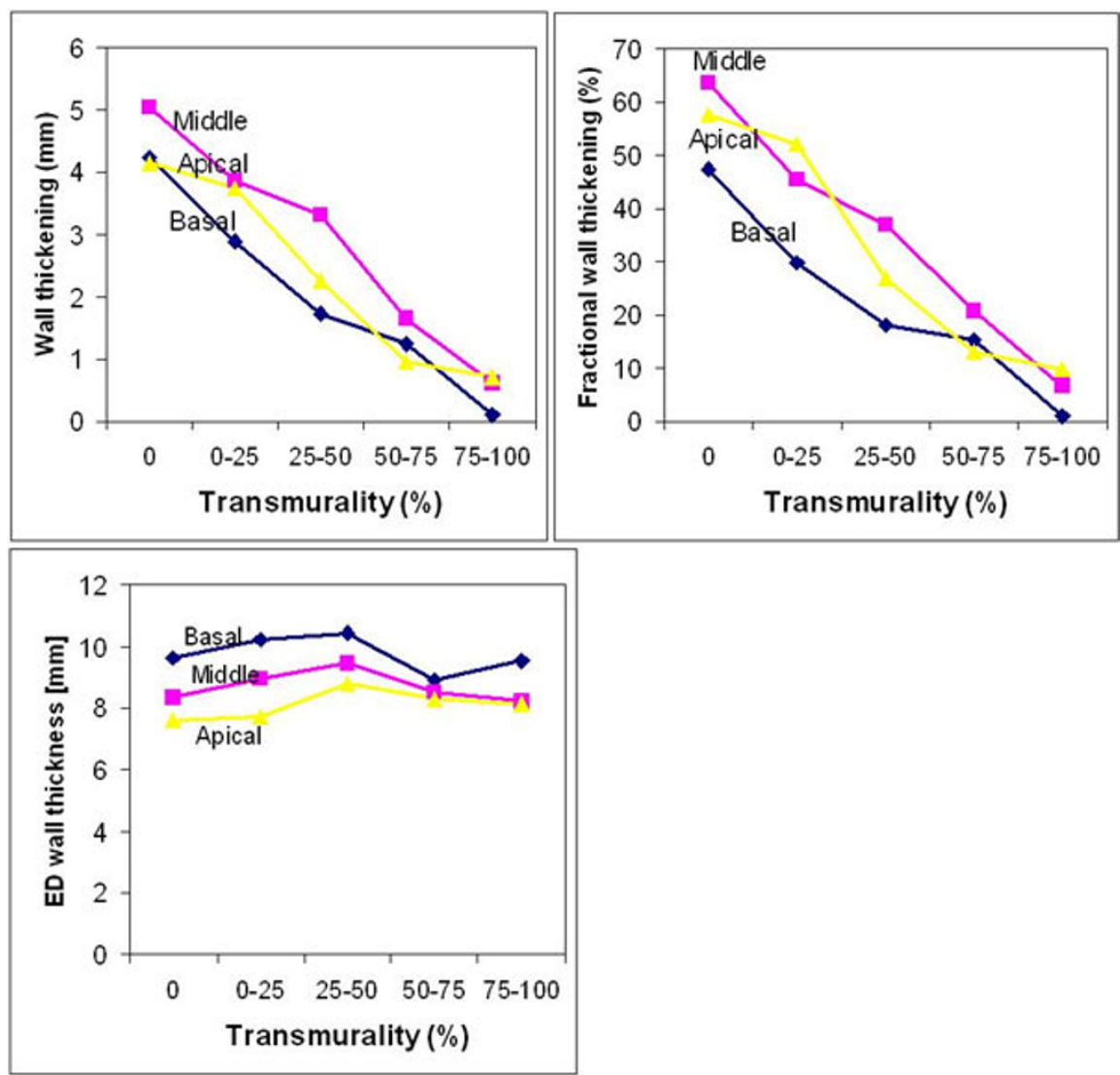

Figure I

Publish with Biomed Central and every scientist can read your work free of charge

"BioMed Central will be the most significant development for disseminating the results of biomedical research in our lifetime. " Sir Paul Nurse, Cancer Research UK

Your research papers will be:

- available free of charge to the entire biomedical community

- peer reviewed and published immediately upon acceptance

- cited in PubMed and archived on PubMed Central

- yours - you keep the copyright 